\title{
INCREASING OF ENERGY EFFICIENCY OF SPINDLES WITH FLUID BEARINGS
}

\author{
Dmytro FEDORYNENKO*, Serhii SAPON*, Sergiy BOYKO*, Anastasiia URLINA* \\ *Chernihiv National University of Technology, Mechanical Engineering Department, 95 Shevchenko Street, Chernihiv, Ukraine \\ fdy1974@gmail.com, s.sapon@gmail.com, svboyko.cstu@gmail.com, urlina.anastasia@gmail.com
}

received 5 October 2015, revised 15 September 2017, accepted 18 September 2017

\begin{abstract}
Promising ways of energy efficiency gain of spindles with fluid flow bearings are offered. New design of journal hybrid flow bearing which contains spherical bearing pockets and adjustable valves with relay control system is offered to improve energy efficiency of spindle units of machine tools. To reduce power losses of fluid bearings at high speed special lubrication based on water with integrated system of corrosion protection is offered. Results of theoretical research of energy consumption of grinding machine tool with a new design of spindle hybrid bearings are presented. Power losses of the spindle unit with both new design and base design of journal bearings are assessed. Effectiveness of new design of spindle hybrid bearings at high operating speeds is shown.
\end{abstract}

Keywords: Energy Efficiency, Power Losses, Hybrid Fluid Bearing, Spindle, Machine Tool, Low Viscosity Lubrication, Corrosion Protection

\section{INTRODUCTION}

According to the data of the works (Diaz et al., 2011; Estomad Project, 2013) great influence on current consumption in the course of processing is made by a spindle drive (about $30 \%$ ) and auxiliary machine tool units (to $60 \%$ from general expenses on electric power). At the same place, it is specified that power consumption by a spindle unit and power consumption for lubricant oil inlet for its lubrication and cooling vary in the range from $50-70 \%$ depending on processing conditions on CNC machine. Energy efficiency of main motion drive will decrease if it works below rated power. On the other hand, maximum allowed power of spindle limits the speed of cutting and productivity of machining process.

Energy efficiency indicators of a spindle unit are mostly provided with a correct choice of type and design of its bearings (Cao et al., 2017). Fluid film bearings provide high rotational accuracy and high indicators of stiffness and damping compared with other types of spindle arrangements. However, at use of viscous lubricant oils as operating liquids hydrostatic bearings are characterized by big losses of capacity on friction and, as a consequence, vigorous heating at increased rotational frequencies (Perovic, 2012; Wardle, 2015). For example, at high-speed cutting on lathes it is established that at rotational frequency of $8000 \mathrm{rpm}$ and cutting capacity of $30 \mathrm{~kW}$ losses on friction in hydrostatic bearings reach 35 kW (Perovic, 2012).

Lubrication of hydrostatic bearings with low viscous liquids, in particular, water presents separate interest considering constantly increasing requirements concerning specific speed of spindles. In work (Nakao et al., 2012) prospects of application of water lubrication is noted, designs of bearings are specified. However, question of anticorrosive protection of bearings and systems of their supply are highlighted insufficiently in technical literature and require further research.
It is commonly known that energy efficiency of spindle drive will decrease at growth of cutting speed which is caused by increase of mechanical and hydraulic power friction loss. According to the data (http://hyprostatik.de) it is established that power loss in high-speed (more than 100,000 rpm) spindle with hydrostatic bearings increases by 3-4 times in comparison with low-speed ones (to 4,000 rpm) and makes about $30 \%$ of spindle drive power.

Thus, there is a contradiction in technological machining system between simultaneous maintenance of high values of productivity and energy efficiency of machining processes on machine tools. Moreover, existing technical solutions of fluid film spindle bearings are designed either for roughing of materials at low cutting speeds or high-speed finishing with low loading on the spindle of machine tool.

Overcoming of the specified contradictions will allow creating machine tools with expanded technological possibilities, by combination of processing with significant loadings, high-speed processing simultaneously providing energy efficiency gain and reduction of production cost.

\section{PROMISING WAYS OF ENERGY EFFICIENCY GAIN OF SPINDLES WITH FLUID FLOW BEARINGS}

Scientific approaches to energy research of machine tools and their components are characterized by a wide variety. Obviously, the most rational one is a systematic approach to designing of energy efficient machine constructions that can analyse elements and subsystems of machines and their interrelationships within a given hierarchical structure.

Regarding spindle units with fluid bearings two promising ways are offered (Fig. 1), namely, energy efficiency gain of exist- 
ing elements of power systems and improving of structure efficiency of control systems.

Analysis of spindle energy flow should be performed in two dimensions: space and time. Spatial dimension involves analysis of energy flows in components and systems of the spindle unit, such as analysis of electricity consumption of spindle drives, analysis of power loss due to friction in bearings. Method of structural analysis is appropriate to identify processes and systems which are characterized by significant power consumption.

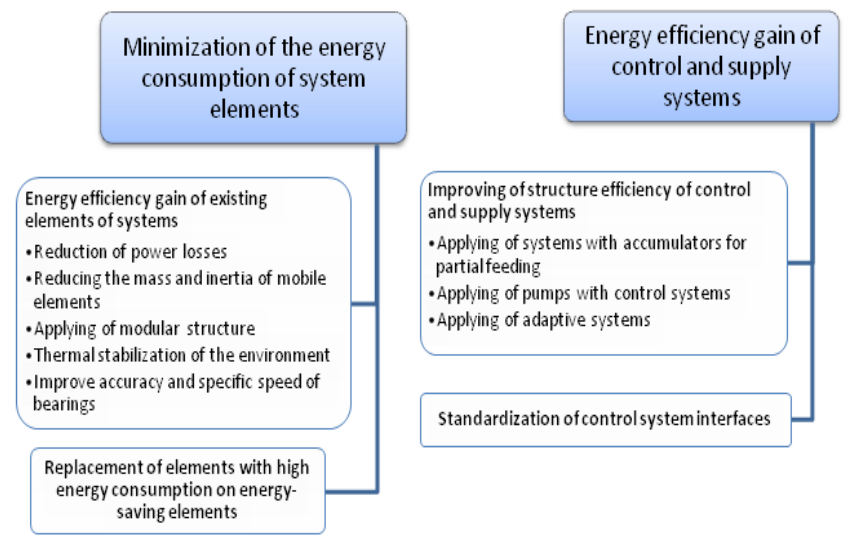

Fig. 1. Promising ways to increase energy efficiency of spindles with fluid bearings

Determination of energy loss can be made through appropriate passport data of separate mechanism subsystems or by known theoretical or empirical relationships. The best option in terms of adequacy of the obtained values of energy loss is experimental research. However, this approach is associated with considerable investments, characterized by long duration and is not always possible, especially in production environment. The most promising approach in terms of preliminary prognosis of energy consumption is the use of special software to analyse energy flow in processing (Estomad Project, 2013), but it requires apriori information on energy options and expanding of libraries of standard elements in order to take into account a broad range of power equipment.

Construction of generalized energy balance allows to identify "narrow" place of systems characterized by significant power consumption. The next phase - synthesis is directed on overcoming of these technical contradictions in the system; it begins with development of mathematical models, usually numerical modelling and experimental studies of mechanisms and machine systems with significant power.

A promising way to reduce power consumption is to decrease power loss in bearing system tools, reducing weight, inertia, acceleration of moving parts while ensuring high rates of accuracy, rigidity and heat resistance. Power loss in spindle units takes place primarily due to energy loss in mechanical and hydraulic elements of system, energy losses in motors.

For example, it was found that high-speed cutting power loss due to friction in the hydrostatic spindle bearing can exceed cutting power (Wardle, 2015; Chasalevris et al., 2016). Search of rational design solutions for units of friction and bearing lubrication systems is determined to minimize energy loss. Improvement of efficiency of hydraulic systems is possible by minimizing of volumetric, mechanical and hydraulic energy losses.

Reduced mass and inertia of moving parts reduces material and energy output of machines in general. Reduction of weight and inertia can reduce reactive power and electric energy loss which affects positively power consumption when accelerating work of the spindle. In addition, weight reduction can reduce energy loss in spindle bearings, raise vibration frequency of the system, and as a result, machining productivity.

Energy efficiency can be also increased due to the modular design structure of hydraulic power units that reduces pressure loss in highways and local supports; thermal stabilization of environment through convective heat removal through the walls of the tank and supply system elements.

Reducing energy consumption is also possible by improving of accuracy and specific speed of spindle bearings. This allows us to use high-speed processing of materials. Compared to the traditional usage high-speed processing can reduce specific energy consumption for processing workpieces by several times (Singh et al., 2012; Zahedi et al., 2015).

Replacement of machine components on energy efficient ones allows saving up to $25 \%$ of consumed electricity (Grossmann, 2015). For example, motors of smaller sizes that are more energy efficient may be also used with a moderate acceleration of moving parts of the machine.

Use of hydraulic accumulators for partial supply of hydraulic executive mechanisms allows to increase efficiency of throttles adjustment and to reduce power consumption by more than three times (Grossmann, 2015).

Use of special regulators (flow rate, pressure and power regulators) allows increasing of pump efficiency in several times. Similar results can be achieved by use of adaptive adjustment based on microprocessor control. It should be noted that one of the most effective solutions for minimization of energy consumption is application of unregulated pumps with frequency control in fluid supply system to spindle bearings.

Efficiency control systems, use of continuous monitoring of energy consumption play significant role in resource saving. Thus, control of machines should be adjusted to minimize energy options while ensuring high performance. Modern machines represent complex mechatronic systems with lots of measuring and converting elements for various purposes and principles of action. Improving of energy efficiency management systems and monitoring can be achieved through standardization and integration of these interfaces (Estomad Project, 2013).

Promising way to improve efficiency of industrial equipment is energy recovery. Regarding machine tools the recovery of kinetic energy during braking of high speed spindles using blocks of capacitors to store electrical energy is the most effective way of energy use (Pfefferkorn et al., 2009; Takabi et al., 2015).

\section{DEVELOPMENT OF HIGH-SPEED HYBRIDFLUID CONSTRUCTION OF THE BEARING}

In Chernihiv National University of Technology design of highspeed hybrid fluid bearing was developed to reduce energy loss and improve rapidity of spindle (Fedorynenko et al., 2014).

Increase of rapidity and efficiency of fluid bearing performance is achieved by spherical bearing pockets to which compressed fluid flows through adjustable fluid valves.

Implementation of bearing pockets to spherical form reduces power consumption caused by abrupt changes of flow form which reduces power loss because of viscous friction while increasing the rotor speed (Badescu, 2016).

Use of adjustable valves for fluid supply to the bearing with in- 
creasing frequency rotor allows stopping fluid flow to pockets of bearing, resulting in proceeds to the hydrodynamic bearing mode, thus reducing power loss as viscous friction and fluid flow. This causes increasing rapidity bearing.

Power system of hybrid fluid adjustable journal bearing is divided into five branches for supply of each of the pockets (Fig. 2). Each of the proportional valves 5-9 are previously adjusted to the required throughput of oil. For adjustment and control of power systems multipoint distribution valve 1 is designed, use of two gauges allows to control pressure in the bearing pockets.

During hydrostatic bearing fluid supply mode compressed fluid comes to five bearing pockets through valves $5-9$, setting up a permanent throughput. Spindle speed is determined by encoder 4, after it a digital signal goes to microprocessor controller 3 .

While speed of spindle exceeds pre-set limit, microprocessor controller 3 disables oil supply to valves $5,8,9$, leaving valve 6 or 7 enabled. As a result, the bearing is operating in the hydrodynamic lubrication mode. While reducing rotation speed below the pre-set limit, controller 3 turns on the flow of the operating fluid to all bearing pockets, thereby restoring hydrostatic lubrication mode to ensure high load carrying capacity and radial stiffness of the bearing when operating at low speeds.

Friction and pumping power losses are reduced by decreasing of fluid supply to pockets in hydrodynamic mode and spherical bearing pockets. It allows increase of operating speed of bearing rotation.

\section{RESEARCH RESULTS OF CONSTRUCTION OF HIGH-SPEED HYBRID FLUID BEARING}

One of the main factors determining possibility of hydraulic lubrication of spindle at high operating speeds is energy loss in bearing spindle hub. Total energy loss in the bearings of hydraulic type consists of viscous friction loss $P_{\mu}$ in oil bearing layers and loss for pumping the operating fluid $P_{q}$.

Estimation of total energy loss in fluid bearing is made using the formula:

$P_{\Sigma}=P_{\mu}+P_{q}$.

Loss of power $P_{\mu}$ and $P_{q}$ in hydrostatic bearing is determined using the formula (Fedorynenko et al., 2016):

$P_{\mu}=0,022 \cdot 10^{-13} \cdot \frac{\mu \cdot D^{3} \cdot n^{2} \cdot\left(L \cdot \theta+l_{o} \cdot \varphi\right)}{\delta}$,

$P_{q}=p_{H} \cdot Q$,

where: $\mu$ - dynamic viscosity fluid, Pa.s.10-3; $D$ - spindle diameter (front bearing), mm; $n$ - spindle speed, rpm; $L$ - length of operating surface of hydrostatic sleeve, $\mathrm{mm} ; I_{0}$ - land axial length, $\mathrm{mm}$; $\delta$ - value of diametrical clearance, $\mathrm{mm} ; \theta$ - angular size of tangential lands, radians; $\varphi$ - corner pocket size in tangential direction, radians; $p_{H}-$ pump pressure, $\mathrm{Pa} ; Q$ - operating fluid flow, $\mathrm{m}^{3} / \mathrm{s}$.

During work in hydrodynamic lubrication mode supply of operating fluid is required only for cooling of viscous zone. Bearing capacity is provided by hydrodynamic effect. Therefore, during hydrodynamic mode it is advisable to supply with operating fluid only one bearing pocket, thus reducing consumption of oil by several times, resulting in corresponding decrease in power loss for pumping of operating fluid in resistance during mode of hydrodynamic lubrication as compared to loss in hydrostatic mode.
It is known (Mahner et al., 2016) that the growth of dynamic viscosity of operating fluid leads to corresponding increase in power loss to viscous friction resistance, and with increasing frequency of spindle this process is more intense.

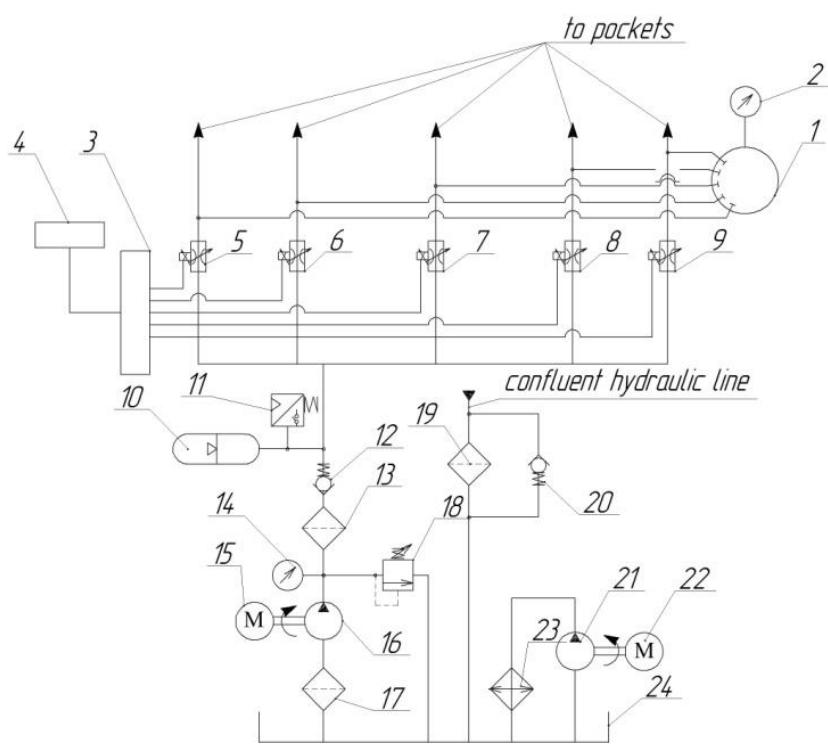

Fig. 2. Power system of controlled journal bearing: 1 - multipoint distribution valve; 2,14 - pressure detectors; 3 - microprocessor controller; 4 - encoder; 5-9 - proportional valves; 10 - accumulator; 11 - pressure switch; 12,20 - check valves; $13,17,19$ - filters; 15,22 - electric motors; 16, 21 - fixed displacement pumps; 18 - pressure relief valve; 23 - coolant device; 24 - tank

Thus, in order to minimize energy loss it is offered to use appropriate operating fluids with low-viscosity (kinematic coefficient of viscosity $v<1 \mathrm{cSt}$ ) for lubrication of high speed spindles. It is offered to use lubricating medium with fluid from distilled water with a complex system of corrosion protection - corrosion inhibitor and protector.

Forming high indicators of corrosion resistance of friction pairs is a determining factor to ensure high operational reliability of spindle bearings in general. Investigation of corrosionelectrochemical behaviour of hydrostatic bushings carried out by a complex system using an electrochemical method and physical and mechanical tests on fatigue.

It is established that the use of corrosion inhibitor $\varepsilon$-caprolaktam with concentration of $1 \mathrm{~g} / \mathrm{L}$ (Tsybulia et al., 2011) is an effective way to protect power system elements of hydrostatic bearing. To increase effectiveness of corrosion protection of the supplies system additional use of electrochemical method was offered. In relation to the inhibition, it does not require constant monitoring. As the tread, we propose use of zinc. Standard electrode potential of zinc in water is $-0.761 \mathrm{~V}$, and iron $-0.44 \mathrm{~V}$, with this combination on zinc will focus on anode process, and on the elements protected by cathode process.

Constructive response tread protection is offered in the form of fitting that is placed in the injection hydraulic line feed system spindle bearings. The fitting is made of zinc, directly connected by tapered thread with manifold injection of hydraulic pumps.

As we can see, use of special low-viscosity lubrication can reduce total energy losses in the bearing by almost 6 times (Fig. 3) comparing to mineral oill- $5 \mathrm{~A}\left(\mu=5 \cdot 10^{-3} \mathrm{~Pa} \cdot \mathrm{s}\right.$, at temperature of 50 degrees Celsius). 
Thus, total energy loss in the modernized bearing is lower by 1.5 times during hydrostatic lubrication mode and 4 times during hydrodynamic mode than loss in the base version of bearing (Fig. 4, a).

a)

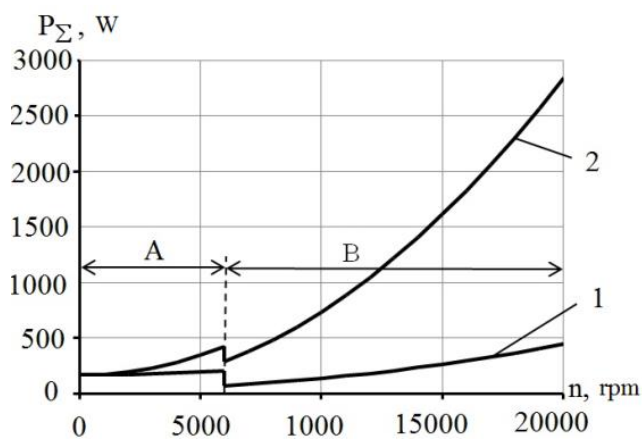

b)

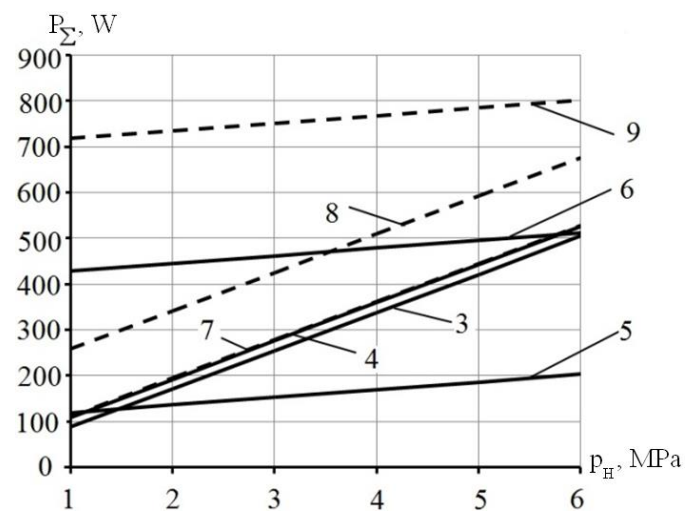

Fig. 3. Dependence of total energy loss $P_{\Sigma}$ in the bearing: $a-$ on the speed $n$ of spindle: 1 - special low-viscosity lubrication, 2 - oil $\mathrm{I}-5 \mathrm{~A} ; \mathrm{A}$ - hydrostatic lubrication mode; $\mathrm{B}$ - hydrodynamic lubrication mode; $b$ - supply pressure $\mathrm{p}_{\mathrm{H}}$ (solid curves - special lowviscosity lubrication; dashed curves - lubrication with oil I-5A): $3,7-n=2,000 \mathrm{rpm} ; 4,8-n=5,000 \mathrm{rpm} ; 5,9-\mathrm{n}=10,000 \mathrm{rpm}$; $6-n=20,000 \mathrm{rpm}$

In Fig. 4, dependence of total energy loss on $P_{\Sigma}$ effective power during grinding $P_{\text {ef }}$ and overall power consumption while grinding details on grinding machine tools $P_{t}\left(P_{t}=P_{\Sigma}+P_{e f}\right)$ on the speed of spindle $n$ is presented.

The developed construction has relay control of lubrication mode which is realised by microcontroller device. The output characteristics of hybrid bearing are changed step-like at transition from hydrostatic to hydrodynamic mode of lubrication and vice versa due to the relay control system of the lubrication mode. As is seen from Figs. 3 and 4 , actuation of the relay controller leads to abrupt change of power losses $P_{\Sigma}, P_{t}$ at spindle speed of 6,000 rpm due to the change of fluid supply to the bearing pockets at transition to another lubrication mode.

With increasing of spindle speed up to $6,000 \mathrm{rpm}$ when the bearing still works in hydrostatic lubrication mode, power $P_{\text {ef }}$ differs by $14 \%$ from $P_{t}$ during processing of the details (final grinding of steel 45). While increase of the speed of rotation from 6,000 to $20,000 \mathrm{rpm}$ takes place at installed hydrodynamic lubrication mode, $P_{\text {ef }}$ relation to $P_{t}$ during processing of the details is in the range of 4 to $7 \%$.

Assessment of energy efficiency of base and modernized bearing of spindle is performed in terms of specific electricity consumption of machine tool $(E p)$ (the ratio of consumed electricity facilities to the volume of products produced during the same time under certain conditions). Energy loss of main motion and total power consumption of auxiliary machinery and machine were taken into consideration while determining specific consumption of electric energy.

a)

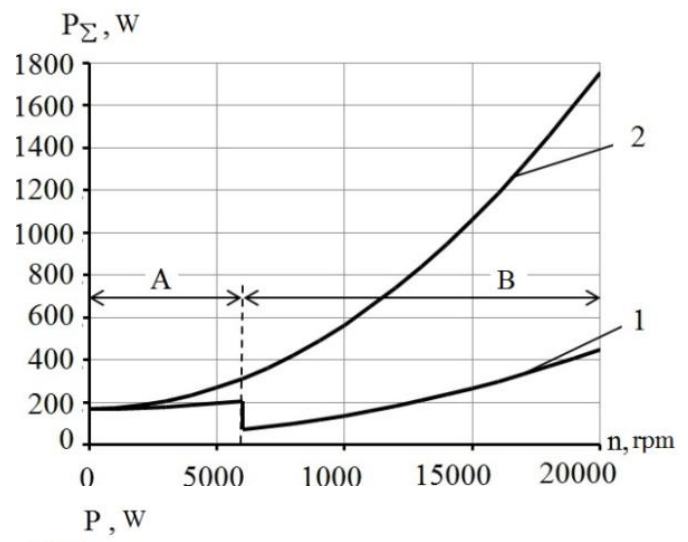

b)

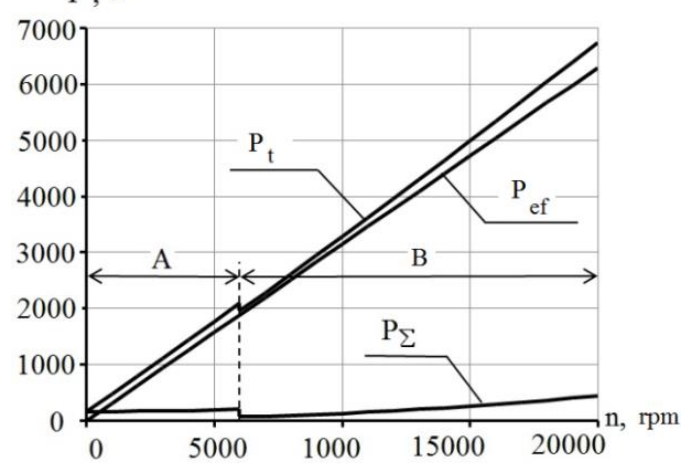

Fig. 4. Dependence of total energy loss $P_{\Sigma}$ (a) and energy losses $P$ during grinding details $(b)$ on the speed $n$ of spindle: 1 - controlled bearing; 2 - prototype; A - hydrostatic lubrication mode; $B$ - hydrodynamic lubrication mode

It was discovered that when spindle rotation speed is up to 10,000 rpm, unit costs of electricity of basic and modernized machines differ slightly. But with increasing of rotational speed up to 20,000 rpm rapid growth of energy consumption base model machine $(E p)$ is observed to value of 2.91 , but power consumption of machine tool with upgraded model of a new type of bearing is 1.2 .

One of the main spindle indicators that determine machining accuracy is bearings stiffness. To evaluate static radial stiffness $C_{b}$ of bearings we used the formula $C_{b}=d W / d e$, where $W-$ radial bearing film force at static loading; $e$ - bearing eccentricity under external force acting.

Bearing film force $W$ can be define as: $W=\sqrt{W_{x}^{2}+W_{y}^{2}}$, where $W_{x}, W_{y}$ - projections of the force $W$ on the coordinate axes $X$ and $Y$ respectively. Let us consider translational movements of bearing journals without misalignment. In such case for idealized bearing surfaces (no account of surfaces imperfection tendencies), we can define forces as:

$W_{x}=\frac{D L}{2} \int_{0}^{2 \pi} p\left(\varphi_{p}\right) \cos \left(\varphi_{p}\right) d \varphi_{p}$
$W_{y}=\frac{D L}{2} \int_{0}^{2 \pi} p\left(\varphi_{p}\right) \sin \left(\varphi_{p}\right) d \varphi_{p}$,

where: $p\left(\varphi_{p}\right)$ - pressure function on the bearing surface; $\varphi_{p}$ - polar angle of the bearing surface. 
Determining pressure function $p\left(\varphi_{p}\right)$ in hydrostatic bearings is a separate and complicated task. The procedure for determination of the pressure function was considered in detail in the works (Fedorynenko et al., 2015; 2016).

Theoretical plots are given for precise lathe UT16A in Fig. 5. As is seen in Fig. 5, stiffness of the prototype and the hybrid bearing in the hydrostatic mode of lubrication are approximately equal. Stiffness of the hybrid bearing in the hydrodynamic lubrication mode (curve 2) is less than the prototype (curve 1) and increases with the spindle speed. It should be noted that stiffness of the hybrid bearing satisfies conditions of a high-speed finish turning machining.

Hydrostatic spindle thermal stability is of key importance to achieve high accuracy of machining. The main sources of heat in the hydrostatic spindle are bearings. In the works (Salazaraet al., 2017; Zuo et al., 2013) it is noted that in order to increase spindle thermal stability it is necessary to minimize heating of the fluid in slide bearings. Fig. 5 shows temperature rise $\Delta T$ for a single pass of lubricant between bearing inlet and outlet of the prototype design (curve 3 ) and hybrid bearing (curve 4) depending on the spindle speed. $\Delta T$ parameter was estimated by formula (Rowe, 2012):

$\Delta T=\frac{p_{H}(1+K)}{\rho c}$

where: $K=P_{\mu} / P_{q} ; \rho$ - fluid density, $\mathrm{kg} / \mathrm{m}^{3} ; c$ - specific heat capacity, J/kg K.

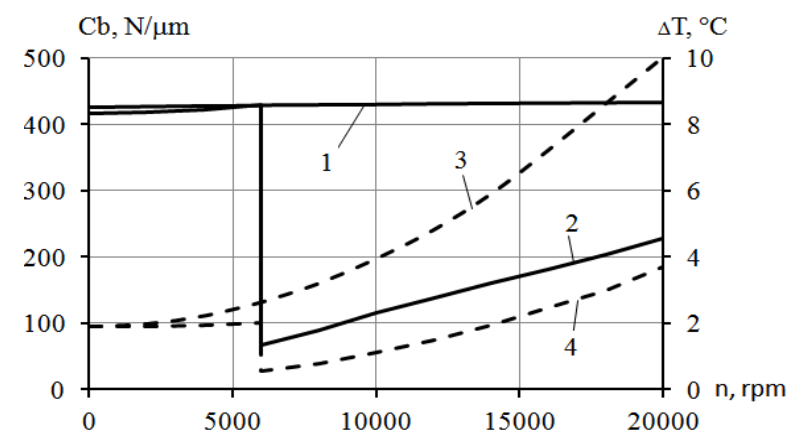

Fig. 5. Radial bearing stiffness $\mathrm{Cb}$ (solid curves) and fluid temperature rise $\Delta \mathrm{T}$ (dashed curves) vs spindle speed $\mathrm{n}: 1,3$ - prototype; 2, 4 - controlled bearing

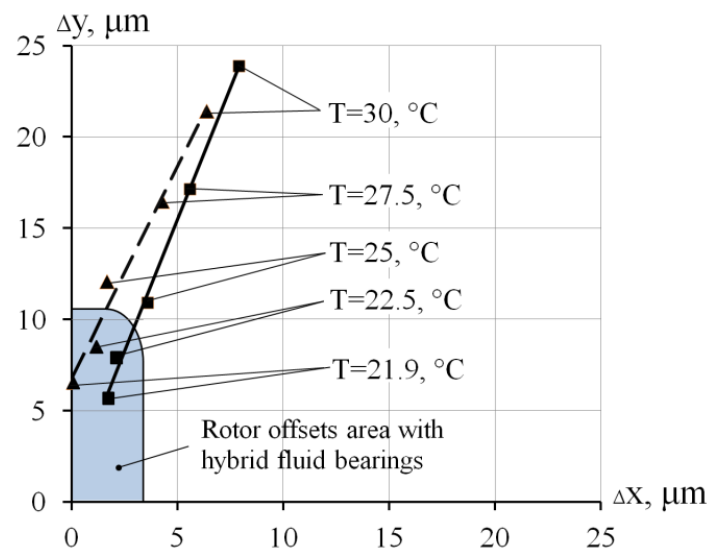

Fig. 6. Experimental values of the rotor thermal offsets $\Delta x, \Delta y$ along $X$ and $Y$ coordinates respectively at turning machining: solid line - pocket pressure equals $2 \mathrm{MPa}$; dashed line - pocket pressure equals $3 \mathrm{MPa}$
As we can see, hybrid spindle bearings design provides fluid heating 2.6 times less that prototype at maximum spindle speed.

Spindle heat resistance is characterized by offset of the spindle axis under the action of thermal field in machining process. Fig. 6 shows offsets $\Delta x, \Delta y$ of the spindle rotor with hydrostatic bearings during turning machining of workpieces depending on the lubricant temperature $T$ inside front bearing. Rotor displacements were measured by laser sensors mounted on two coordinate axes $X$ and $Y$ at distance of $200 \mathrm{~mm}$ from the front spindle bearing. Precise mandrel was installed in the rotor to measure spindle offsets. The workpieces were fixed to the mandrel by a special fixing device. The method of experimental studies of rotor offsets is considered in detail in the works (Fedorynenko et al., 2016; Huang et al., 2016).

Increase of lubricant temperature due to friction in the hydrostatic bearing leads to a substantial displacement of the rotor on its overhang area. Increase of pockets pressure in the bearing up to $3 \mathrm{MPa}$ reduces the rotor offsets up to 2 times in a horizontal plane. Use of a hybrid design of spindle bearings makes it possible to reduce rotor thermal offsets by 3-4 times at turning machining in comparison with the prototype.

\section{CONCLUSIONS}

Developed scientific approaches can be used to improve energy performance of high-speed fluid bearings of spindles as well as to design new facilities based on analysis of similar purpose.

According to the results shown in the article, due to a new design of controlled journal hybrid bearing it was possible to reduce total energy loss in enhanced resistance by 1.5 times during hydrostatic lubrication mode and 4 times during hydrodynamic mode compared to loss in the base version of the bearing. Beside this, application of the hybrid bearings allows us to reduce spindle thermal offsets at turning machining up to 4 times compared with hydrostatic journal bearings.

Effective way to improve energy efficiency of spindles with fluid bearings is application of operating fluids with low viscosity. Use of special lubrication based on water with corrosion inhibitor ( $\varepsilon$ - caprolaktam) can reduce energy loss in journal bearing almost by 6 times at spindle speed 20,000 rpm compared with lubrication by mineral oils.

It is established that with spindle speed of 20,000 rpm energy consumption of lather machine tool with the new design of journal spindle bearings is reduced by 2.4 times in comparison to the base one.

Prospects for future research include experimental validation of received theoretical results and optimization of bearings design to find optimal solutions for energy efficiency and productivity.

\section{REFERENCES}

1. Badescu V. (2015), Optimal profiles for one dimensional slider bearings under technological constraints, Tribology International, 90, 198-216.

2. Cao H, Zhang X., Chen X. (2017), The concept and progress of intelligent spindles: A review, International Journal of Machine Tools and Manufacture, 112, 21-52.

3. Chasalevris A., Dohnal F. (2016), Improving stability and operation of turbine rotors using adjustable journal bearings, Tribology International, 104, 369-382. 
4. Diaz N., Redelsheimer E., Dornfeld D. (2011), Energy Consumption Characterization and Reduction Strategies for Milling Machine Tool Use, Sustainability in Manufacturing. Energy Efficiency in Machine Tools, $263-267$.

5. EC - 7th Framework Programme. Challenge 6: ICT for Mobility, Environmental Sustainability and Energy Efficiency. Deliverable D3.3: "Design for energy efficiency" (2013), Estomad Project.

6. Fedorynenko D., Boyko S., Sapon S. (2015), The search of the spatial functions of pressure in adjustable hydrostatic radial bearing, Acta Mechanica et Automatica, 9(1), 23-26.

7. Fedorynenko D., Boyko S., Sapon S. (2016), Accuracy of spindle units with hydrostatic bearings, Acta Mechanica et Automatica, 10(2), 117-124.

8. Fedorynenko D., Sapon S. (2016), Spindle Hydrostatic Bearings (in Ukrainian), ChNUT.

9. Fedorynenko D., Sapon S., Habibulina A. (2014), Adjustable Journal Hybrid Fluid Bearing, Patent of Ukraine No 89288.

10. Grossmann K. (2015), Thermo-energetic Design of Machine Tools, Springer International Publishing.

11. Huang P., Lee W., Chan C. (2016), Investigation on the position drift of the axis average line of the aerostatic bearing spindle in ultraprecision diamond turning, International Journal of Machine Tools and Manufacture, 108, 44-51.

12. Mahner M, Lehn A., Schweizer B. (2016), Thermogas- and thermohydrodynamic simulation of thrust and slider bearings: Convergence and efficiency of different reduction approaches, Tribology International, 93, 539-554

13. Nakao Y., Mimura M., Kobayashi F. (2012), Water energy drive spindle supported by water hydrostatic bearing for ultra-precision machine tool, http://www.researchgate.net/publication/228896125.

14. Perovic B. (2012), Hydrostatic guides and bearings: basic principles, calculation and design of hydraulic diagrams (in German), SpringerVerlag Berlin Heidelberg.
15. Pfefferkorn F., Lei S., Jeon Y., Haddad G. (2009), A metric for defining the energy efficiency of thermally assisted machining, International Journal of Machine Tools and Manufacture, 49, 357-365.

16. Rowe W.B. (2012), Hydrostatic, aerostatic and hybrid bearing design, Butterworth-Heinemann Press.

17. Salazara J, Santosa I. (2017), Active tilting-pad journal bearings supporting flexible rotors: Part I - The hybrid lubrication, Tribology International, 107, 94-105.

18. Singh V., Venkateswara Rao P., Ghosh S. (2012), Development of specific grinding energy model, International Journal of Machine Tools and Manufacture, 60, 1-13.

19. Takabi J., Khonsari M. (2015), On the thermally-induced seizure in bearings: A review, Tribology International, 90, 118-130.

20. Tsybulia S., Fedorynenko D., Kostenko I., Buialska N. (2011), Corrosion Protection of Elements of Spindle Hydrostatic Bearing of Machine Tools (in Ukrainian), Materials of the XI International Conference: Efficiency Implementation of Scientific, Resource and Industrial Facilities in Modern Terms, Kyiv.

21. Wardle F. (2015), Ultra Precision Bearings, Elsevier.

22. Zahedi A., Tawakoli T, Akbari J. (2015), Energy aspects and workpiece surface characteristics in ultrasonic-assisted cylindrical grinding of alumina-zirconia ceramics, International Journal of Machine Tools and Manufacture, 90, 16-28.

23. Zuo X., Wang J., Yin Z., Li S. (2013), Comparative performance analysis of conical hydrostatic bearings compensated by variable slot and fixed slot, Tribology International, 66, 83-92.

24. http://hyprostatik.de/fileadmin/inhalte/pdfs/hydrostatic spindles.pdf

Acknowledgement: The presented results are part of projects 0113 U000503 "Development of the Precision-Controlled Hydraulic Bearings of High-Speed Spindle Units" and 0115U002362 "Development of Energy-Efficient High-Speed Spindles with the Adaptive Journal Bearings" funded by the Government of Ukraine. 